\title{
Implementation of the WHO Framework Convention on Tobacco Control in Tunisia: Progress and challenges
}

\author{
Chahida Harizi ${ }^{1,2}$, Fatimah El-Awa ${ }^{3}$, Habib Ghedira' ${ }^{2,4}$, Carmen Audera-Lopez ${ }^{5}$, Radhouane Fakhfakh ${ }^{1,2}$
}

\begin{abstract}
InTRoduction The World Health Organization Framework Convention on Tobacco Control (WHO FCTC) was the first health treaty that requires state parties to adopt and implement the MPOWER package. The aim of this study is to review the current status of tobacco control policies in Tunisia according to the WHO FCTC recommendations.

METHODS This paper is a critical narrative literature review in which information was obtained from peer-reviewed articles, official government documents, reports, decrees and grey literature in French, Arabic and English.

RESULTS Modest progress in FCTC implementation in Tunisia was noted. The smoking ban in public places is not regularly or largely enforced. The advertising and promotion for tobacco and its products is prohibited by law, but, the ban does not cover the display and visibility of tobacco products at points-of-sale, through the internet, and the depiction of tobacco or tobacco use in entertainment media products. Health warnings on tobacco products consist only of text and do not exceed $30 \%$ of the main display areas but are expected to increase to $70 \%$ with graphics and text when the new law is passed.

CONCLUSIONS Effective intervention efforts are urgently required. These actions should include accelerating the adoption of a new law, enforcing the present law and the new one once adopted, developing an advocacy and argument about the positive impact on state budget balance, increasing taxes, combating smuggling and illicit manufacturing and counterfeiting, increased education, increased smoking cessation support and implementing periodic surveillance.
\end{abstract}

\author{
AFFILIATION \\ 1 Department of Epidemiology \\ and Statistics, Abderrahmen Mami \\ Hospital, Ariana, Tunisia \\ 2 Faculty of Medicine of Tunis, \\ University of Tunis El Manar, Tunis, \\ Tunisia \\ 3 World Health Organization, \\ Regional Office for the Eastern \\ Mediterranean, Cairo, Egypt \\ 4 Department of Pneumonology, \\ Abderrahmen Mami Hospital, \\ Ariana, Tunisia \\ 5 World Health Organization, WHO \\ Framework Convention on Tobacco \\ Control, Convention Secretariat, \\ Geneva, Switzerland
}

CORRESPONDENCE TO Chahida Harizi. Department of Epidemiology and Statistics, Abderrahmen Mami Hospital, Ariana, Tunisia. E-mail: chahidaharizi@hotmail.fr

\section{KEYWORDS}

tobacco policy, WHO Framework Convention on Tobacco Control, MPOWER, Tunisia

Received: 19 June 2020

Revised: 7 October 2020

Accepted: 14 November 2020

\section{INTRODUCTION}

Tobacco consumption is one of the major public health problems worldwide. It continues to be the most preventable cause of death, accounting for more than 7 million victims a year. By 2030, ten million tobacco-related deaths will have occurred; most of them will be in developing countries ${ }^{1}$.

Tunisia has a tobacco use prevalence in the top ten worldwide among men and the highest in Africa of $53 \%$, whereas the prevalence among women ranges from $1.1 \%$ to $8 \%^{2-9}$.
Tobacco-related cancer incidence was estimated at 5000 cases in 2012 and this incidence will increase by $80 \%$ in 2030 . Half of regular smokers will die of a smoking-related disease, losing a decade of life on average $^{2}$. Tobacco-related mortality is also increasing and more men die in Tunisia than on average in middle-income countries ${ }^{10}$.

As a global response to the globalization of the tobacco epidemic, international efforts led by WHO resulted in the development of the WHO Framework Convention on Tobacco Control (WHO FCTG) ${ }^{11}$ 
adopted in 2003 and entered into force in 2005.

Having been signed by 168 countries and being legally binding in 181 countries, the FCTC is considered as 'the most rapidly and widely embraced treaty in the United Nations history'. In 2008, WHO introduced MPOWER - a package of six high impact and proven measures that help countries reduce their demand for tobacco. These measures include: Monitoring tobacco use and prevention policies; Protecting people from tobacco smoke; Offering help to quit tobacco use; Warning about the dangers of tobacco; Enforcing bans on tobacco advertising, promotion and sponsorship; and Raising taxes on tobacco $^{12}$.

Tunisia signed the WHO FCTC on 22 August 2003 and ratified it on 7 June 2010. There are still challenges for Tunisia to be fully compliant with the WHO FCTC ${ }^{13}$.

In this article, our aim is to review the current status of FCTC implementation in Tunisia with respect to the six measures of the WHO MPOWER policy package ${ }^{12}$ and to describe the progress and challenges of its implementation.

\section{METHODS}

\section{Design}

This is a critical narrative literature review in which information was obtained from peer-reviewed articles, official government documents, reports, decrees, and grey literature in French, Arabic and English.

\section{Search strategy and data sources}

Both online and manual search methods were used to collect the information. In terms of online search, we used three main browsers PubMed, Google Scholar and WHO Library Database (WHOLIS). To search for articles published on PubMed, we used the Mesh terms 'tobacco use cessation' and 'health legislation'. For the two other browsers, the main keywords used were: 'tobacco control', 'policies', 'the Framework Convention on Tobacco Control', 'MPOWER', and 'Tunisia'. Boolean operators AND/OR were used with the keywords to find combination documents. The keywords used for each component of the MPOWER package are given in Table 1.

The searches were conducted between January and May 2019, and were updated in September 2020. Searches were limited to articles from 1980 to 2020. Manual search was performed to obtain unpublished literature reviews, including reports by research institutes, government and nongovernmental documents, as well as legal documents including tobacco control law, corresponding decrees, circulars, and related official documents.

\section{Study selection and inclusion/exclusion criteria}

The MPOWER components were used as an organizational framework to classify the items to be included. Research which addressed any of these components was included. Documents that did not directly assess any of the MPOWER measures in Tunisia, such as description of types of tobacco used or perceptions of smoking, were not included. All types of literature including research reports, literature reviews, journal articles, fact sheets, government documents, decrees and theses were included. English, French and Arabic literature was used, and other languages excluded.

\section{Data extraction and management}

The full text of each relevant article was read and assessed against predefined inclusion and exclusion criteria. Relevant data were extracted and classified according the main elements of MPOWER.

\section{Patient and public involvement}

No patient was involved.

Table 1. Details of keywords used for searching each component of the MPOWER Package

\begin{tabular}{|c|c|}
\hline Topics & $\begin{array}{l}\text { Addition keywords (along with } \\
\text { the main keywords) }\end{array}$ \\
\hline M - Monitor use and policies & $\begin{array}{l}\text { 'monitoring', 'surveillance } \\
\text { system' }\end{array}$ \\
\hline $\begin{array}{l}\text { P - Protect from secondhand } \\
\text { smoke }\end{array}$ & $\begin{array}{l}\text { 'tobacco free', 'secondhand } \\
\text { smoke }^{* \prime}\end{array}$ \\
\hline $\begin{array}{l}0 \text { - Offer help to quit tobacco } \\
\text { use }\end{array}$ & $\begin{array}{l}\text { 'smoking cessation*', 'offer to } \\
\text { quit', 'NRT' }\end{array}$ \\
\hline W - Warn of dangers & $\begin{array}{l}\text { 'pictorial health warning', } \\
\text { 'graphic health warning' }\end{array}$ \\
\hline E - Enforce TAPS ban & $\begin{array}{l}\text { 'tobacco advertising', } \\
\text { 'tobacco promotion', 'tobacco } \\
\text { sponsorship', 'TAPS ban' }\end{array}$ \\
\hline $\mathrm{R}$ - Raise taxes on tobacco & $\begin{array}{l}\text { 'tobacco tax implementation', } \\
\text { 'Tobacco Control Fund' }\end{array}$ \\
\hline
\end{tabular}

${ }^{*}$ Mesh terms. 


\section{RESULTS}

\section{Key milestones in terms of tobacco control policies in Tunisia}

With regard to the danger of smoking, the Tunisian legislature has intervened to protect public health by promulgating various texts relating to the fight against smoking. The first legal framework for tobacco control in Tunisia is represented by Law $\mathrm{N}^{\circ}$ 98-17 of 23 February 1998 on prevention of the harmful effects of smoking ${ }^{14}$. This law regulates notably direct advertisement and smoking ban in public places. The main purpose of this law is to alert people to the dangers of smoking and thereby limit morbidity, premature death, and human suffering caused by tobacco use. This law was then strengthened with the smoke free public places Decree $\mathrm{N}^{\circ}$ 98-2248 fixing the collective use places where it is forbidden to smoke ${ }^{15}$ supplemented by Decree $\mathrm{N}^{\circ} 2009-2611$ of 14 September $2009^{16}$.

This legislative framework was completed by the accession of Tunisia to the WHO Framework Convention on Tobacco Control which was ratified on 7 June 2010. The WHO Tobacco Free Initiative focuses on helping countries, particularly those with low or middle incomes, to build and enforce the most effective tobacco control policies, programs, and strategies.

In order to ensure the implementation of the WHO FCTC on country-level, WHO has introduced the MPOWER package with six proven technical tobacco control measures. The MPOWER measures include: 1) Monitoring tobacco use and prevention policies; 2) Protecting people from tobacco smoke; 3) Offering help to quit tobacco use; 4) Warning about the dangers of tobacco; 5) Enforcing bans on tobacco advertising, promotion and sponsorship; and 6) Raising taxes on tobacco.

\section{$\mathrm{M}$ - Monitor tobacco use and prevention policies}

Are actions to monitor tobacco use and prevention policies developed in Tunisia?

In Tunisia, monitoring related activities for tobacco use among adolescents was performed through The Tunisian Global Youth Tobacco Survey on students aged 13-15 years (GYTS, in 2001, 2007, 2010 and 2017). Therefore, key information on tobacco use including smoking prevalence, secondhand smoking, cessation, media etc., has been continuously updated and monitored.

However, the Global Adult Tobacco Survey (GATS) has not been conducted in Tunisia. Monitoring related activities for tobacco use among adults was combined with some national surveys such as the national survey of chronic obstructive pulmonary disease (COPD) conducted in 1996 on a representative national sample of 5696 people aged 25 years $^{3}$. Some recent national surveys were similarly conducted such as the hypertension national survey among Tunisian adults conducted between 2004 and $2005^{5}$ and the BREATHE study conducted between 2011 and $2012^{17}$. However, there is a need for periodic collection of data. It is therefore recommended that regular youth and adult surveys be conducted at least every 5 years at national level.

\section{P - Protect people from tobacco smoke}

What laws and anti-tobacco regulation texts are there to protect people from tobacco smoke? And what is the degree of their application?

In view of the danger of tobacco on public health, various legal texts relating to the tobacco control were promulgated in Tunisia. The first one was Law $\mathrm{N}^{\circ} 98-$ 17 of 23 February 1998 relative to prevention of the harmful effects of smoking ${ }^{14}$.

This law introduced for the first time in Tunisia the smoking ban in public places. It forbids smoking in 'areas designated for common use'. The application Decree $\mathrm{N}^{\circ} 98-2248^{15}$ came then to specify these public places where smoking is restricted, namely: schools, public or private sanitary establishments, premises of leisure and sport intended to welcome minors, mosques and places of cult, rooms of meetings and conferences of the public service. The methods of planning smoking areas within premises for collective use were subsequently defined in Decree $\mathrm{N}^{\circ} 2009-2611^{16}$, taking into account their size, layout, conditions of use, airing, and ventilation.

Nevertheless, to be in full compliance with the FCTC, Tunisia should move forward to a full public smoking ban. Indeed, the FCTC Article 8 Guidelines require a $100 \%$ smoke-free law ${ }^{11}$. This is because scientific evidence has proven that the only effective way to protect the public from secondhand smoke 
is to fully ban smoking in all indoor workplaces and indoor public places ${ }^{18}$.

The Association of Health may have a role through raising awareness about the new law in educational facilities, healthcare facilities, dental clinics, and family medicine centers, where they rely on the role of children in promoting home prevention with their teachers and parents.

On the other hand, the tobacco control law $1998 / 17^{14}$ prohibits the use of slot machines to limit sales, in particular to children.

However, there are still no measures implemented to prohibit the sales of tobacco products to minors in Tunisian law and no provision in the current tobacco control law requires the sellers of tobacco products to place a notice at points-of-sale about the prohibition of tobacco sales to minors. Also, sellers are not required by law to request, in case of doubt, that a purchaser provide appropriate evidence of having reached the required legal age. Consequently, and according to 2017 GYTS, $76.7 \%$ of youth aged 13-15 years were able to buy cigarettes from a store ${ }^{19}$. It is therefore recommended that the Government include in the new bill an article that addresses this point and ensures its enforcement by law.

\section{0 - Offer help to quit tobacco use}

Who are the actors and what are the key measures regarding tobacco dependence and smoking cessation? In 2005, a cross-sectional study was conducted in the largest Tunisian hospital, Charles Nicolle Hospital, to assess knowledge, attitudes and practices of health professionals towards smoking (Fakhfakh R, Boujemmaa, Ben Salah F, Gharbi R, Klouze A, Lakhal M, Belkahia C, Achour N. Smoking habits, knowledge and attitudes among hospital staff in Tunisia. 4th Annual Conference of the International Society for the Prevention of Tobacco Induced Diseases, Athens, Greece, 30 September to 2 October 2005). The results showed that $27.6 \%$ of health professionals believed that 'lower tar and nicotine cigarettes are less harmful' and $15 \%$ believed that narghile is not harmful. Forty-two per cent did not find a link between tobacco and bladder cancer, and $21 \%$ believed that tobacco does not cause cancer of the mouth. These misperceptions may have a significant impact on physicians' knowledge regarding smoking cessation treatments, particularly nicotine replacement therapy (NRT), and their willingness and ability to provide smoking cessation advice. Also, in this study, only $62 \%$ of health professionals were aware of the existence of a smoking cessation support clinic in their hospital, and $43.3 \%$ of the doctors had already referred patients to this type of service, whereas only $6.6 \%$ had already received training on smoking cessation. In addition, the prevalence of smoking among medical staff was high $(51 \%$ of men, $10.4 \%$ of women, and in total $26.9 \%$, were current smokers), while $46.3 \%$ admitted smoking in front of their patients. This smoking behavior of medical staff constitutes a barrier to their ability to offer effective help to other smokers. Five years later (in 2010), another study conducted in Mami Hospital revealed similar results, suggesting that the ability of Tunisian medical staff to offer help in tobacco control is weak ${ }^{20}$. A recent study conducted in 2017 in Sahloul Hospital in the central-eastern Tunisia showed that $21 \%$ of healthcare workers were smokers and two-thirds reported smoking in their workplace. This study also showed that $20 \%$ of all health workers were tolerant of patient smoking ${ }^{21}$. It is therefore recommended that the training provided for healthcare workers in giving brief advice and encouraging quit attempts be strengthened. It is also recommended that national programs and services on diagnosis and treatment of tobacco dependence, and counselling services on cessation of tobacco use, be established and promoted in different settings as required under Article 14 of the Convention (e.g. educational institutions, healthcare facilities, primary healthcare centers, workplaces, and sporting environments).

At university level, medical and paramedical students receive a special course on tobacco, detailing epidemiology and control, integrated into their curriculum and in postgraduate studies. Moreover, a new cessation program was recently implemented through mobile phone messages.

A second important pillar next to educational action is smoking cessation assistance. The first cessation clinic was set up in Tunisia in 1999, and now more than 69 cessation clinics have been established in Tunisia, of which 49 are in primary healthcare centers. Nicotine Replacement Therapy (NRT) is the only cessation medication in Tunisia; it is available but with frequent stock shortages. 
The National Health Service insurance fully covers the cost of cessation medications. However, the medical insurance systems do not cover the cost of cessation medications, which are not on the country's essential drug list. Not all pharmaceutical products for treatment of tobacco dependence (e.g. bupropion and varenicline) are freely available in the public health service. There is no national quitline. It is therefore recommended that Tunisia facilitate accessibility and affordability of pharmaceutical products for treatment of tobacco dependence; also, a national toll-free quitline for cessation of tobacco use should be established.

\section{W - Warn about the dangers of tobacco}

What measures concerning public awareness are there using packaging and labelling of tobacco products?

The Order of the Minister of Health of 20 May 2014, amending the order of 24 February $1999^{22}$, regulates warning labels and requires the conditions for the registration of the information placed on the outside cover of tobacco packages. The law stipulates that the outer cover of every cigarette package must contain a clear warning about the harmful effects of smoking such as 'Important: Smoking is harmful to your health'. This warning must be conspicuous, easily legible and understandable and on an area not less than $30 \%$ of the main exhibition space. It must be written in Arabic and in a foreign language. The law stipulates also that the composition, and the nicotine and tar contents, must be mentioned on the packaging.

While textual warnings can potentially inform tobacco consumers of the risks associated with tobacco products, more is required from Tunisia with regard to the topic of packaging. The WHO recommends- in accordance with FCTC Article 11that state parties employ pictorial (or graphic) health warnings on tobacco products. Graphic warnings depicting images of the health consequences of using tobacco have- pursuant to the WHO-caused tobacco consumption rates to fall ${ }^{23}$. Specifically, empirical research conducted after the implementation of pictorial package warnings in Canada, Brazil, Singapore and Thailand concluded that pictorial warnings significantly increase people's awareness of the harms of smoking ${ }^{24-26}$.

The main shortcomings of the Tunisian law are it does not mandate pictorial health warnings and requires only one textual health warning that covers only $30 \%$ of the main display areas. Moreover, descriptors depicting flavors are not prohibited. In response to these weaknesses, a new bill is proposed to have more comprehensive regulations to be in line with the guidelines of Article 11 of the Convention ${ }^{11}$. The requirements for effective tobacco packaging and labeling in this proposed bill would be to add pictorial health warnings occupying at least 50\% of the main display areas, to place the warning at the top of the package and to choose a font of appropriate size and color. As for warnings relating to packaging, they must be rotating and must not be masked in any way whatsoever, including mandatory markings such as tax stamps. Tobacco packaging and labelling is required not to use misleading terms that imply the product is less harmful than other similar products, such as 'low tar', 'light', 'ultralight', or 'mild'. Also required in this bill is not to use descriptors depicting flavors, to ban the display of quantitative information on emission yields (such as tar, nicotine, and carbon monoxide) on tobacco packaging, including when used as part of a brand name or trademark, to mandate the display of qualitative information on relevant constituents and emissions of tobacco products on tobacco packaging, and to display on the packaging/labeling the expiry date and quitline number.

\section{E - Enforce bans on tobacco advertising, promotion and sponsorship}

What is the degree of implication of anti-tobacco regulation texts consisting for bans on tobacco advertising, promotion and sponsorship?

The tobacco control law prohibits direct advertisement for tobacco and its products. The ban concerns the media (radio, television, and posters), publications intended for youth, and the sponsoring of sporting or cultural events intended for minors. Advertisement inside tobacco shops, within written press not intended for minors and some sporting events reserved for motor vehicles represent some exceptions to the restrictions on tobacco advertising. This law shows that Tunisia has a comprehensive ban on tobacco advertising, promotion, and sponsorship. However, the ban does not cover the display and visibility of tobacco products at points-of-sale, 
through the internet and the depiction of tobacco or tobacco use in entertainment media products. Sponsorship is only partly addressed in the tobacco control law (in sports events), while the law does not ban direct and indirect funds or in-kind contributions by tobacco companies. According to the 2010 GYTS $^{27}$, $86.7 \%$ of students saw anti-smoking media messages in the past 30 days, $61.3 \%$ saw pro-cigarette ads in newspapers or magazines in the past 30 days, 10.7\% had an object with a cigarette brand logo, and $4.3 \%$ were offered free cigarettes by a tobacco company representative. It is therefore recommended that the ministry of health and other relevant stakeholders develop a strategy to detect violations of the ban on tobacco advertising, promotion and sponsorship and strengthen enforcement, especially in the surroundings of schools.

\section{$\mathrm{R}$ - Raise taxes on tobacco}

What are the price and tax measures applied by the Tunisian government to reduce the demand for tobacco? How effective are they?

The rise in tobacco prices certainly has a deterrent effect on cigarette consumption. It is considered by WHO and the World Bank as the most effective measure to fight against tobacco consumption ${ }^{28,29}$. It is generally estimated that a $10 \%$ increase in the price is necessary to bring about a $4 \%$ decrease in the number of smokers in developed countries and $4-8 \%$ in low- and middle-income countries where lower incomes tend to make them more aware of price developments ${ }^{30}$. In addition, young people are three times more sensitive to the price factor than older people ${ }^{31}$. This makes price interventions have a significant impact on this age group.

The current taxation system in Tunisia is not aligned with the WHO recommended taxation system. The guidelines refer to WHO technical manual on tobacco tax administration ${ }^{32}$ which recommends that tobacco excise taxes account for at least $70 \%$ of the retail prices for tobacco products. According to the WHO Report on the Global Tobacco Epidemic 2015 $5^{33}$, the retail price of the lowest cost brand (Bousetta) of 20 cigarettes was 0.40 TND ( 1 Tunisian Dinar about 0.36 US\$); $2.25 \mathrm{TND}$ for the average sold brand (20 Mars inter légère); and 6.0 TND for the most sold brand (Marlboro). According to the same report, the annual tax revenue from tobacco products in Tunisia was about 1.062 billion TND. A recent increase in the prices of tobacco products took place in 2020 , though it was not due to an increase in tax that determined the final price of tobacco products. This increase in price without tax represents a big problem since it will adversely affect the taxation system, and will negatively affect the achievements of Tunisia in that field. Also, tax rates do not take into account changes in household incomes and inflation. Moreover, there are no taxes imposed on snuff tobacco and smokeless tobacco.

It is therefore recommended that the Government monitor, increase or adjust tobacco tax rates on a regular basis, potentially annually, taking into account inflation and income growth developments in order to reduce the consumption of tobacco products. To this end, Tunisia should consider having regular adjustment processes or periodic reevaluation of tobacco tax levels. This should be accompanied by strong tax administration such as strengthening enforcement agencies to minimize tax evasion by manufacturers and criminal organizations.

\section{CONCLUSIONS}

The tobacco epidemic is well established in Tunisia, a gateway to Africa, particularly among men and increasingly among women ${ }^{10}$. Sociocultural factors favoring smoking initiation, the lack of awareness among the public about the smoking hazards, the weak support of governments and the strong resistance of the tobacco industry are major reasons for the lack of effectiveness of the current tobacco control measures. Therefore, firm actions should be taken. These actions will include accelerating the adoption of a new law, enforcing the present law and the new one once adopted, developing an advocacy and argument about the positive impact on state budget balance, increasing taxes, combating smuggling and illicit manufacturing, increased education, increased smoking cessation support and implementing periodic surveillance.

\section{REFERENCES}

1. World Health Organization. Fact Sheet on Tobacco and Oral Health. Copenhagen, Denmark: World Health Organization; 2018. https://www.euro.who.int/_data/ assets/pdf_file/0005/369653/Fact-Sheet-on-Tobaccoand-Oral-Health-2018-eng.pdf. Accessed October 7, 
2020.

2. Eriksen M, Mackay J, Ross H. The Tobacco Atlas. 4th ed. Atlanta, GA: American Cancer Society, New York, NY: World Lung Foundation; 2012.

3. Fakhfakh R, Hsairi M, Maalej M, Achour N, Nacef T. Tobacco use in Tunisia: behaviour and awareness. Bull World Health Organ. 2002;80(5):350-356. https:// www.who.int/bulletin/archives/80(5)350.pdf. Accessed October 7, 2020.

4. Elasmi M, Feki M, Sanhaji H, et al. [Prevalence of conventional cardiovascular risk factors in the Great Tunis population]. Rev Epidemiol Sante Publique. 2009;57(2):87-92. doi:10.1016/j.respe.2008.12.010

5. Ben Romdhane H, Ben Ali S, Skhiri H, et al. Hypertension among Tunisian adults: results of the TAHINA project. Hypertens Res. 2012;35(3):341-347. doi:10.1038/hr.2011.198

6. Maatoug J, Harrabi I, Hmad S, et al. Clustering of risk factors with smoking habits among adults, Sousse, Tunisia. Prev Chronic Dis. 2013;10:E211. doi:10.5888/pcd10.130075

7. Belfki H, Ben Ali S, Aounallah-Skhiri H, et al. Prevalence and determinants of the metabolic syndrome among Tunisian adults: results of the Transition and Health Impact in North Africa (TAHINA) project. Public Health Nutr. 2013;16(4):582-590. doi:10.1017/S1368980012003291

8. Daldoul H, Denguezli M, Jithoo A, et al. Prevalence of COPD and tobacco smoking in Tunisia - results from the BOLD study. Int J Environ Res Public Health. 2013;10(12):7257-7271. doi:10.3390/ijerph10127257

9. Saidi O, Malouche D, O'Flaherty M, et al. Assessment of cardiovascular risk in Tunisia: applying the Framingham risk score to national survey data. BMJ Open. 2016;6(11):e009195. doi:10.1136/bmjopen-2015-009195

10. Saidi O, Hajjem S, Zoghlami N, et al. Premature mortality attributable to smoking among Tunisian men in 2009. Tob Induc Dis. 2019;17(November):1-8. doi:10.18332/tid/112666

11. World Health Organisation. WHO Framework Convention on Tobacco Control. Geneva, Switzerland: World Health Organization; 2003. https://apps.who.int/iris/bitstream/ handle/10665/42811/9241591013.pdf? sequence $=1$. Accessed October 7, 2020.

12. World Health Organisation. MPOWER: A policy package to reverse the tobacco epidemic. Geneva, Switzerland: World Health Organization; 2008. https://www.who.int/ tobacco/mpower/mpower_english.pdf. Accessed October 7, 2020.

13. Ben Amar W, Chakroun A, Zribi M, Khemekhem Z, Ben Jemaa F, Maatoug S. [Anti tobacco legislation and regulation in Tunisia: between shortcomings and lack of application]. Journal de l'Information Médicale de Sfax. 2017;27:21-26. https://www.medecinesfax.org/ useruploads/files/jim27.pdf. Accessed October 7, 2020.

14. Law No. 98-17 on Prevention of Harmful Effects of
Smoking. [Official newspaper of the Tunisian Republic]. 1998;17:399-400. https://www.tobaccocontrollaws.org/ files/live/Tunisia/Tunisia $\% 20-\% 20$ Prevention $\% 20$ of $\% 20$ Harmful\%20Effects\%20of\%20Smoking.pdf. Accessed October 7, 2020.

15. [Ministry of Public Health]. Decree No. 98-2248 Identifying Smoke-Free Public Places. https://www. tobaccocontrollaws.org/files/live/Tunisia/Tunisia\%20 -\%20Identifying\%20Smoke-Free\%20Public\%20Places. pdf. Published November 16, 1998. Accessed October 7, 2020.

16. [Ministry of Transport]. Decree No. 2009-2611 of September 14, 2009. Journal Officiel de la République Tunisienne. 2009;75:2716-2717. https://www. tobaccocontrollaws.org/files/live/Tunisia/Tunisia $\% 20$ -\%20Decree\%20No.\%202009-2611\%20\%20-\%20national. pdf. Accessed October 7, 2020.

17. Khattab A, Javaid A, Iraqi G, et al. Smoking habits in the Middle East and North Africa: results of the BREATHE study. Respir Med. 2012;106(Suppl 2):S16-S24. doi:10.1016/S0954-6111(12)70011-2

18. Tumwine J. Implementation of the framework convention on tobacco control in Africa: current status of legislation. Int J Environ Res Public Health. 2011;8(11):4312-4331. doi:10.3390/ijerph8114312

19. Ministry of Public Health. Global Youth Tobacco Survey: Fact Sheet Tunisia 2017. https://extranet.who.int/ ncdsmicrodata/index.php/catalog/355/related_materials. Published October, 2018. Accessed October 7, 2020.

20. Ammar J, Abid Ouali H, Berraies A, Hamzaoui A. [Smoking prevalence in A Mami hospital of Ariana: prospective study about 700 health professionals]. Tunis Med. 2013;91(12):705-708.

21. Khefacha Aissa S, Ghali H, Ben Rejeb M, et al. [Smoking attitudes and behavior of the hospital staff Sahloul (Sousse, Tunisia)]. Rev Mal Respir. 2018;35(3):256-263. doi:10.1016/j.rmr.2017.12.001

22. Ministry of Health, Republic of Tunisia. Order of the Minister of Health dated 20 May 2014, amending the order dated 24 February 1999, fixing the inscription methods of the mentions which shall be laid on the external cover of the packages and packing containing tobacco products exposed directly to the consumer, the analysis methods making it possible to measure the content of nicotine and tar in the afore mentioned products as well as the checking methods of the exactitude of these mentions. Official Gazette of the Republic of Tunisia. 2014;43:428. http://www.legislation.tn/sites/default/files/fractionjournal-officiel/2014/2014G/043/Tg201408394.pdf. Accessed October 7, 2020.

23. Fong GT, Hammond D, Hitchman SC. The impact of pictures on the effectiveness of tobacco warnings. Bull World Health Organ. 2009;87(8):640-643. doi:10.2471/blt.09.069575

24. Azagba S, Sharaf MF. The effect of graphic cigarette 
warning labels on smoking behavior: evidence from the Canadian experience. Nicotine Tob Res. 2013;15(3):708717. doi:10.1093/ntr/nts194

25. Volchan E, David IA, Tavares G, et al. Implicit motivational impact of pictorial health warning on cigarette packs. PLoS One. 2013;8(8):e72117. doi:10.1371/journal.pone.0072117

26. Yong HH, Fong GT, Driezen P, et al. Adult smokers' reactions to pictorial health warning labels on cigarette packs in Thailand and moderating effects of type of cigarette smoked: findings from the international tobacco control southeast Asia survey. Nicotine Tob Res. 2013;15(8):1339-1347. doi:10.1093/ntr/nts241

27. World Health Organization. Global Youth Tobacco Survey: Country reports. http://www.emro.who.int/images/ stories/tfi/documents/gyts_cr_tun_2010.pdf. Published 2012. Accessed October 7, 2020.

28. Chaloupka FJ, Powell LM, Warner KE. The Use of Excise Taxes to Reduce Tobacco, Alcohol, and Sugary Beverage Consumption. Annu Rev Public Health. 2019;40:187-201. doi:10.1146/annurev-publhealth-040218-043816

29. Shang C, Chaloupka FJ, Fong GT, Thompson M, O'Connor RJ. The association between tax structure and cigarette price variability: findings from the ITC Project. Tob Control. 2015;24(Suppl 3):iii88-iii93. doi:10.1136/tobaccocontrol-2014-051771

30. World Bank. Curbing the epidemic: governments and the economics of tobacco control. Development in practice series. Jha P, Chaloupka FJ, eds. Washington, DC: World Bank; 1999. http://documents1.worldbank.org/curated/ en/914041468176678949/pdf/multi-page.pdf. Accessed October 7, 2020.

31. Ding A. Youth are more sensitive to price changes in cigarettes than adults. Yale J Biol Med. 2003;76(3):115124. PMID:15369626.

32. World Health Organisation. WHO technical manual on tobacco tax administration. Geneva, Switzerland: World Health Organization; 2010. https://apps.who.int/iris/ bitstream/handle/10665/44316/9789241563994_eng. pdf?sequence=1. Accessed October 7, 2020 .

33. World Health Organisation. WHO report on the global tobacco epidemic, 2015: Raising taxes on tobacco. Geneva, Switzerland: World Health Organization; 2015. https://apps.who.int/iris/bitstream/ handle/10665/178574/9789240694606_eng. pdf?sequence=1. Accessed October 7, 2020.
CONFLICTS OF INTEREST

The authors have completed and submitted the ICMJE Form for Disclosure of Potential Conflicts of Interest and none was reported.

FUNDING

There was no source of funding for this research.

PROVENANCE AND PEER REVIEW

Not commissioned; externally peer reviewed. 